\title{
Support for HTCondor high-throughput computing workflows in the REANA reusable analysis platform
}

\begin{tabular}{|c|c|c|c|c|c|c|c|c|c|}
\hline $\begin{array}{c}\text { Rokas } \\
\text { Mačiulaitis }\end{array}$ & Paul Brenner & Scott Hampton & $\begin{array}{l}\text { Michael D. } \\
\text { Hildreth }\end{array}$ & $\begin{array}{c}\text { Kenyi Paolo } \\
\text { Hurtado } \\
\text { Anampa }\end{array}$ & Irena Johnson & Cody Kankel & Jan Okraska & $\begin{array}{c}\text { Diego } \\
\text { Rodriguez }\end{array}$ & Tibor Šimko \\
\hline CERN & $\begin{array}{l}\text { University of } \\
\text { Notre Dame }\end{array}$ & $\begin{array}{l}\text { University of } \\
\text { Notre Dame }\end{array}$ & $\begin{array}{l}\text { University of } \\
\text { Notre Dame }\end{array}$ & $\begin{array}{l}\text { University of } \\
\text { Notre Dame }\end{array}$ & $\begin{array}{l}\text { University of } \\
\text { Notre Dame }\end{array}$ & $\begin{array}{l}\text { University of } \\
\text { Notre Dame }\end{array}$ & CERN & CERN & CERN \\
\hline $\begin{array}{l}\text { Switzerland } \\
\text { as.maciulaitis@cern.ch }\end{array}$ & $\begin{array}{l}\text { United States } \\
\text { paul.r.brenner@nd.edu }\end{array}$ & $\begin{array}{l}\text { United States } \\
\text { shampton@nd.edu }\end{array}$ & $\begin{array}{c}\text { United States } \\
\text { mhildret@nd.edu }\end{array}$ & $\begin{array}{l}\text { United States } \\
\text { khurtado@nd.edu }\end{array}$ & $\begin{array}{l}\text { United States } \\
\text { ijohnso1@nd.edu }\end{array}$ & $\begin{array}{c}\text { United States } \\
\text { ckankel@nd.edu }\end{array}$ & $\begin{array}{c}\text { Switzerland } \\
\text { jan.okraska@cern.ch }\end{array}$ & $\begin{array}{c}\text { Switzerland } \\
\text { diego.rodriguez@cern.ch }\end{array}$ & $\begin{array}{l}\text { Switzerland } \\
\text { tibor.simko@cern.ch }\end{array}$ \\
\hline
\end{tabular}

\section{Reproducible research}

\section{REANA approach}

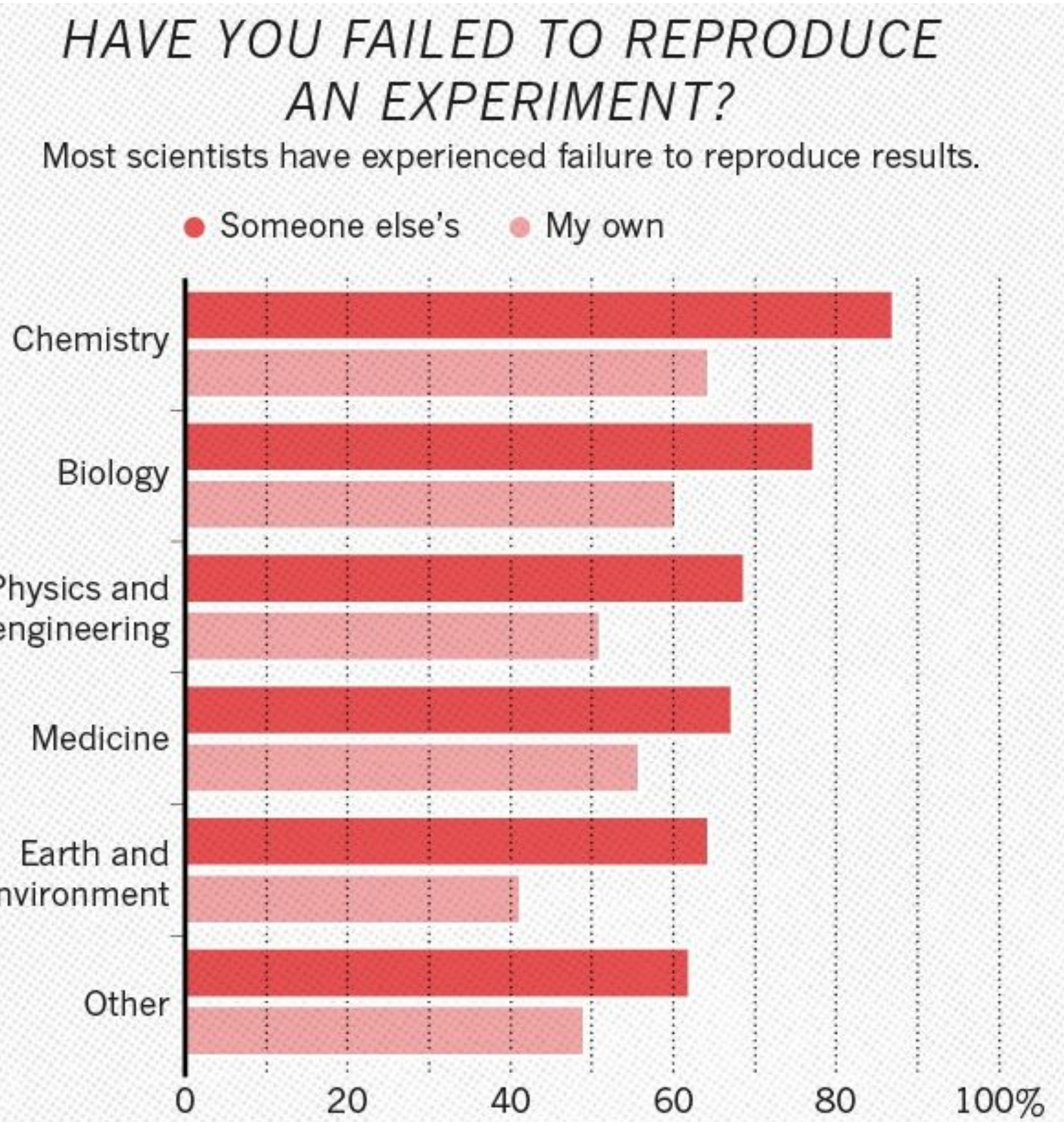

https://www.nature.com/news/1-500-scientists-lift-the-lid-onreproducibility-1.19970

\section{Example workflow}
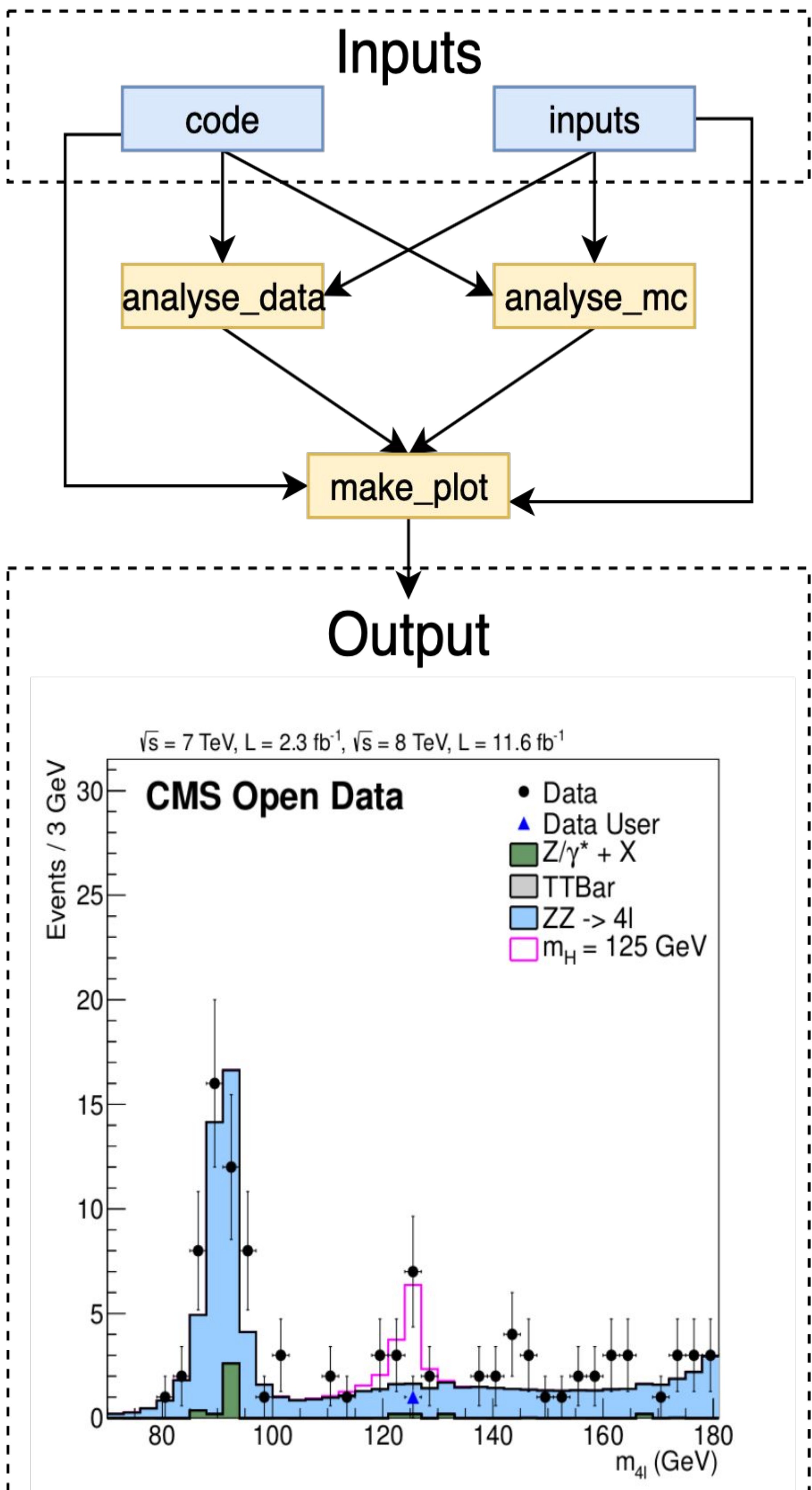

This REANA reproducible analysis example studies the Higgs-to-four-lepton decay channel that led to the Higgs boson experimental discovery in 2012. The example uses CMS open data taken in 2011 and 2012.

https://github.com/reanahub/reana-demo-cms-h4

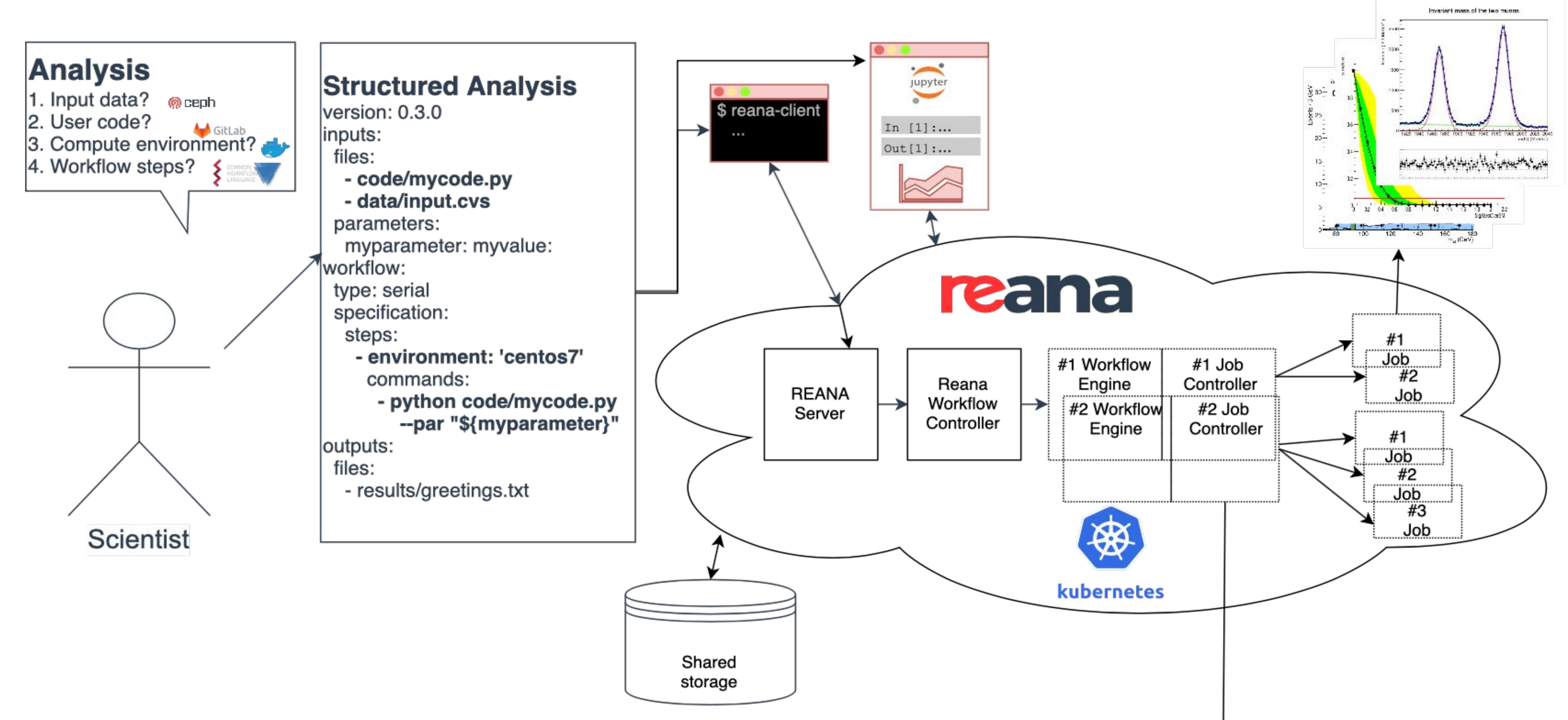

Extending REANA with HICondor

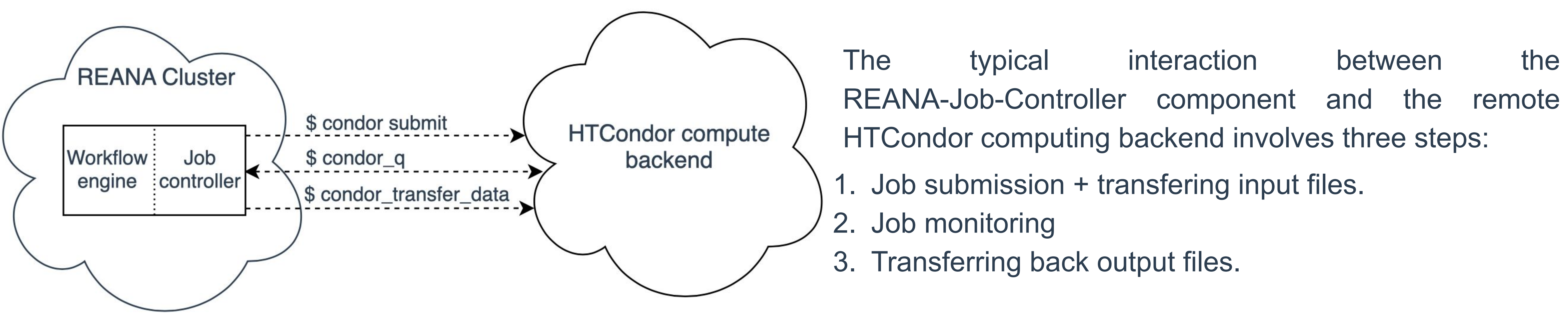

Kubernetes

HTCondor

\section{Abstracting job submission}

The REANA platform submits analysis workflow steps through the Job-Controller component which takes inputs, container image, and commands to run to perform the workflow step tasks. The job controller component then launches the job using the Kubernetes Job API. We have taken existing REANA-Job-Controller REST API and extended the design to support arbitrary compute backend such as

HTCondor

high-throughput computing or Slurm for high-performance computing. The abstraction regards job submission and execution, job status monitoring, and the input/output data transfer amongst supported backends.

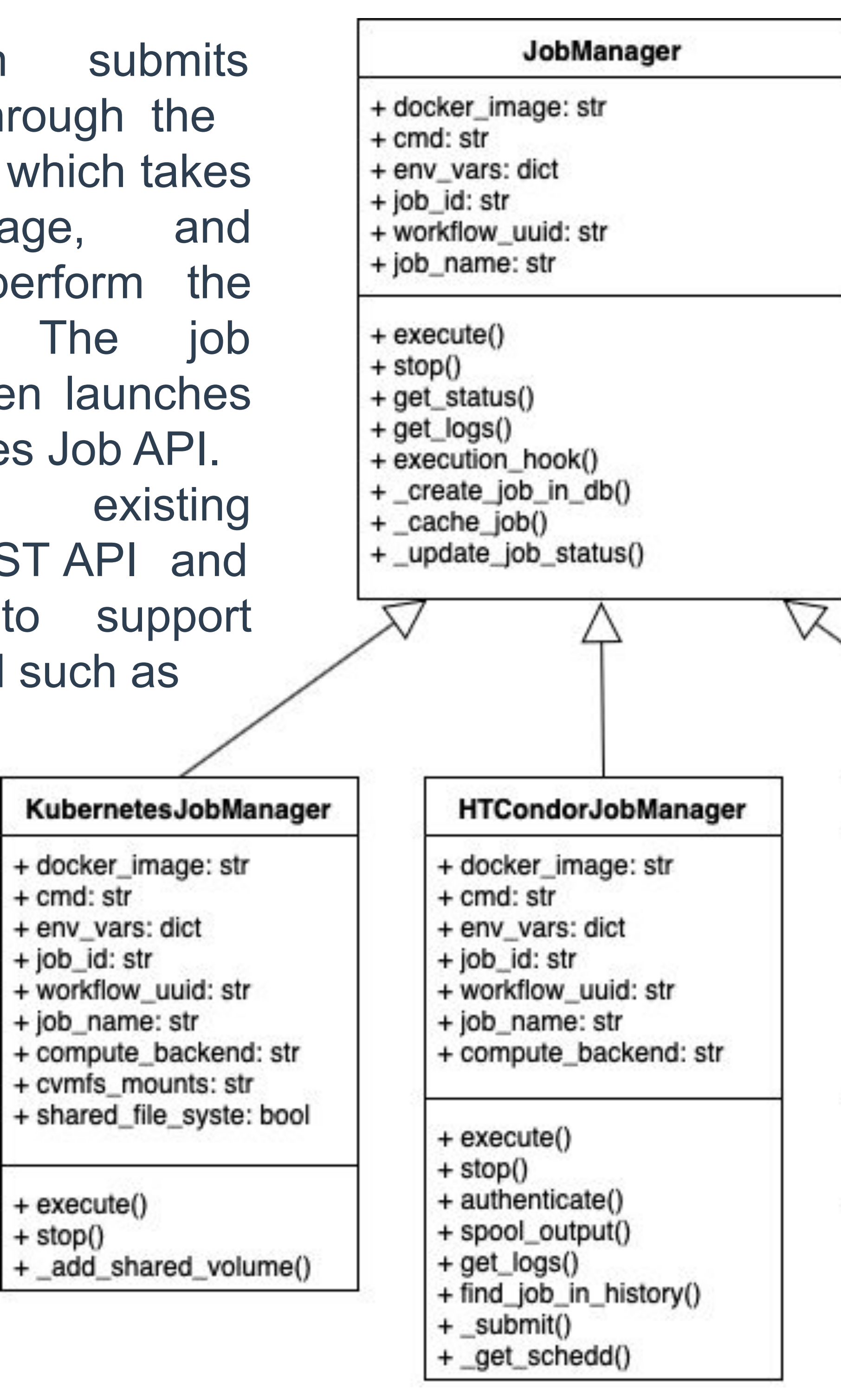

\section{Validation}

The designed solution was prototyped in the REANA platform using the CERN HTCondor cluster. When a user specifies that a certain workflow job is to be run on the HTCondor backend, the REANA-Job-Controller container takes care of job parameter translation for the targeted compute backend. The developed prototype was tested by means of running several particle physics model analyses. The configurable level of "map-reduce" operations in the DAG workflow graph allows to further study the scalability of the solution. We have furthermore integrated REANA with the Virtual Clusters for Community Computation (VC3) environment. We have developed Ansible templates allowing individual users to deploy the personal REANA system in a VC3 environment. The deployment benefits from integration with a range of high-throughput computing backend that the VC3 environment natively supports. Our design was thus validated by means of two independent deployment scenarios. 